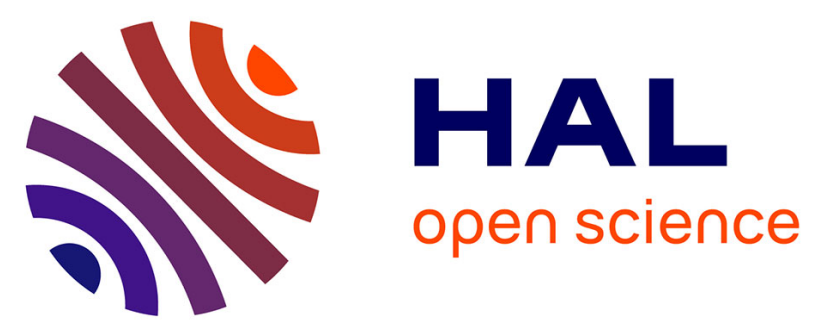

\title{
Cell-type- and region-specific modulation of cocaine seeking by micro-RNA-1 in striatal projection neurons
}

Benoit Forget, Elena Martin Garcia, Arthur Godino, Laura Domingo

Rodriguez, Vincent Kappes, Pierre Poirier, Andry Andrianarivelo, Eric

Senabre Marchan, Marie-Charlotte Allichon, Mélanie Marias, et al.

\section{To cite this version:}

Benoit Forget, Elena Martin Garcia, Arthur Godino, Laura Domingo Rodriguez, Vincent Kappes, et al.. Cell-type- and region-specific modulation of cocaine seeking by micro-RNA-1 in striatal projection neurons. Molecular Psychiatry, 2022, 27, pp.918-928. 10.1038/s41380-021-01328-2 . hal-03432265v2

\section{HAL Id: hal-03432265 \\ https://hal.science/hal-03432265v2}

Submitted on 17 Nov 2021

HAL is a multi-disciplinary open access archive for the deposit and dissemination of scientific research documents, whether they are published or not. The documents may come from teaching and research institutions in France or abroad, or from public or private research centers.
L'archive ouverte pluridisciplinaire HAL, est destinée au dépôt et à la diffusion de documents scientifiques de niveau recherche, publiés ou non, émanant des établissements d'enseignement et de recherche français ou étrangers, des laboratoires publics ou privés. 


\title{
Cell-type- and region-specific modulation of cocaine seeking by micro-RNA-1 in striatal projection neurons
}

\author{
Benoit Forget $\mathbb{D i D}^{1,2,3,4,5,13^{凶}}$, Elena Martin Garcia ${ }^{6}{ }^{6}$, Arthur Godino $\mathbb{D}^{1,2,3,4,7}$, Laura Domingo Rodriguez ${ }^{6}$, Vincent Kappes ${ }^{1,2,3,4}$, \\ Pierre Poirier ${ }^{1,2,3,4}$, Andry Andrianarivelo ${ }^{1,2,3,4,8,9,10}$, Eric Senabre Marchan ${ }^{6}$, Marie-Charlotte Allichon ${ }^{1,2,3,4}$, Mélanie Marias ${ }^{1,2,3,4}$, \\ Peter Vanhoutte ${ }^{1,2,3,4}$, Jean-Antoine Girault (iD ${ }^{2,11,12}$, Rafael Maldonado (D) ${ }^{6}$ and Jocelyne Caboche (iD) $1,2,3,4,13 \bowtie$
}

(c) The Author(s) 2021

The persistent and experience-dependent nature of drug addiction may result in part from epigenetic alterations, including noncoding micro-RNAs (miRNAs), which are both critical for neuronal function and modulated by cocaine in the striatum. Two major striatal cell populations, the striato-nigral and striato-pallidal projection neurons, express, respectively, the D1 (D1-SPNs) and D2 (D2-SPNs) dopamine receptor, and display distinct but complementary functions in drug-evoked responses. However, a cell-typespecific role for miRNAs action has yet to be clarified. Here, we evaluated the expression of a subset of miRNAs proposed to modulate cocaine effects in the nucleus accumbens (NAc) and dorsal striatum (DS) upon sustained cocaine exposure in mice and showed that these selected miRNAs were preferentially upregulated in the NAc. We focused on miR-1 considering the important role of some of its predicted mRNA targets, Fosb and Npas4, in the effects of cocaine. We validated these targets in vitro and in vivo. We explored the potential of miR-1 to regulate cocaine-induced behavior by overexpressing it in specific striatal cell populations. In DS D1-SPNs miR-1 overexpression downregulated Fosb and Npas4 and reduced cocaine-induced CPP reinstatement, but increased cue-induced cocaine seeking. In DS D2-SPNs miR-1 overexpression reduced the motivation to self-administer cocaine. Our results indicate a role of miR1 and its target genes, Fosb and Npas4, in these behaviors and highlight a precise cell-type- and region-specific modulatory role of miR-1, illustrating the importance of cell-specific investigations.

Molecular Psychiatry; https://doi.org/10.1038/s41380-021-01328-2

\section{INTRODUCTION}

Drug addiction is a clinically devastating neuropsychiatric disorder thought to result from neural adaptations at the molecular, cellular, and circuit levels, following repeated drug exposure [1]. Drugs of abuse initially affect neuronal plasticity in the mesocorticolimbic system corresponding to dopamine (DA) neurons of the ventral tegmental area (VTA) projecting onto the ventral part of the striatum, the nucleus accumbens (NAc), and the prefrontal cortex $[2,3]$. The striatum plays crucial roles in diverse behavioral processes including movement control and reward-dependent learning [4-6]. While the NAc underlies the primary reinforcing effects of drugs of abuse such as cocaine, the emergence of compulsive cocaine-seeking habits, a hallmark of drug addiction, is associated with a shift to the dorsal striatal (DS) control over behavior [7, 8].

In the DS, and to a lesser extent in the NAc, striatal projection neurons (SPNs) are comprised of two segregated GABAergic neuronal populations: the SPNs expressing the DA-D1 receptor subtype (D1-SPNs) that project directly to the internal segment of the globus pallidus (GPi) and the substantia nigra pars reticulata $(\mathrm{SNr})$, and the SPNs expressing the DA-D2 receptor subtype (D2-
SPNs), which project mainly to the external segment of the globus pallidus (GPe). Furthermore, these two subpopulations exert distinct, albeit complementary, functions. In the DS the D1-SPNs represent the "direct pathway", which activation facilitates the initiation and execution of movement, while the activation of D2SPNs of the "indirect pathway" inhibit movement $[9,10]$. However, both pathways are necessary for action initiation [11]. The direct and indirect pathways are also thought to work in opposing manners in reward-based learning, with the activation of the direct pathway promoting reinforcement and the indirect pathway mediating punishment and aversion [5, 12], although such a dichotomy has been recently challenged [13-15]. Several studies investigated the participation of D1- and D2-SPNs in behaviors related to cocaine exposure [16]. For example, activation of D1SPNs in the NAc increases the formation of cocaine reward-context associations, while activation of D2-SPNs in the same structure decreases cocaine reward and self-administration (SA) $[17,18]$. D1SPNs in the NAc encode information related to the association between cocaine and contextual cues and drive cocaine seeking induced by those cues [19]. While most of the studies investigating

\footnotetext{
${ }^{1}$ Neuroscience Paris Seine, Institut de Biologie Paris-Seine, Paris, France. ${ }^{2}$ Sorbonne Université, Faculty of Sciences, Paris, France. ${ }^{3}$ CNRS UMR8246, Paris, France. ${ }^{4}$ INSERM U1130, Paris, France. ${ }^{5}$ Human Genetics and Cognitive Functions, Institut Pasteur, rue du Docteur Roux, Paris, France. ${ }^{6}$ Laboratory of Neuropharmacology, Department of Experimental and Health Sciences, Universitat Pompeu Fabra (UPF), Barcelona, Spain. ${ }^{7}$ Department of Neuroscience and Friedman Brain Institute, Icahn School of Medicine at Mount Sinai, New

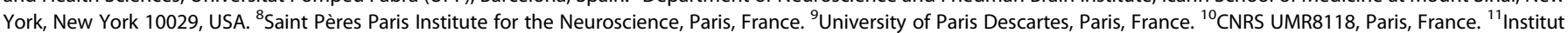

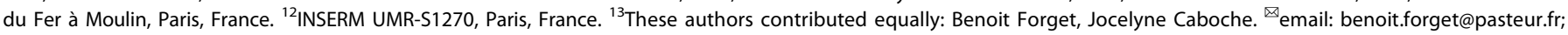
jocelyne.caboche@upmc.fr
}

Received: 14 May 2020 Revised: 16 September 2021 Accepted: 28 September 2021

Published online: 16 November 2021 
the role of D1- and D2-SPNs in the behavioral effects of cocaine focused on the NAc, a recent work showed a very specific role of D1-SPNs of the dorsomedial striatum in cocaine responses, where their inhibition had no impact on loss of control over cocaine intake, motivation to obtain cocaine or compulsive cocaine selfadministration, but specifically reduced cue-induced cocaine seeking in high-risk addiction groups of rats [20].

The persistent and experience-dependent aspects of the addicted phenotype have suggested a role for epigenetic modifications in drug-induced gene expression [21] as epigenetic mechanisms can register and durably maintain transcriptional states [22]. Among various epigenetic processes, attention has recently been focused on miRNAs, a subcategory of 21-25nucleotides non-coding RNAs that modulate gene expression by binding to complementary sequences in the $3^{\prime}$ untranslated regions ( $3^{\prime} U T R$ ) of many, up to hundreds, target mRNA transcripts per miRNA, thereby inducing mRNA destabilization and subsequent degradation and/or repression of mRNA translation [23]. Changes in miRNAs expression levels have been shown to play a role in multiple neuronal functions and are altered in several psychiatric conditions [24], including addiction [25]. Several studies have provided evidence that miRNA-mediated gene regulation plays an important role in cocaine-induced changes in neurotransmission and behavior [26], but there is so far no direct evidence regarding cell-type-specificity of cocaine-induced miRNA in the striatum, and more specifically in D1-SPNs versus D2-SPNs. One study began to broadly address this aspect by specific ablation in D2-SPNs of Ago2 [27], a key protein in the processing and production of miRNAs [28-30]. These mice showed loss of motivation to self-administer cocaine, along with a decrease of around one third of miRNAs induced by acute cocaine, thus indicating that miRNA induction occurs in both D1and D2-SPNs. However, the question of whether and how miRNAs regulation in D1-SPNs versus D2-SPNs controls gene expression and behaviors induced by cocaine, remains to be addressed.

Here we aimed to identify the regional pattern, i.e. DS versus NAc, of expression of a set of selected miRNAs, proposed to play a key role in cocaine action or neuronal plasticity after sub-chronic cocaine administrations [24, 25, 31]. We observed an increase in the expression of several miRNAs, including miR-1, in the Nacc but not the DS. MiR-1 targets included 2 mRNAs involved in addiction processes: fosb and npas4. Interestingly, fos $b$ and npas 4 mRNA levels were upregulated by cocaine in the DS but not the NAcc, leading us to hypothesize that the absence of miR-1 upregulation in the DS might allow their induction in that area, while their induction was blunted by miR-1 in the NAc. In line with this homeostatic hypothesis, we next investigated the effect of miR-1 overexpression in D1- or D2-SPNs of the NAC or DS in multiple behaviors related to cocaine addiction by using a validated viral strategy [32-34]. We found a key role of miR-1 overexpression in D1-SPNs of the DS in cocaine and cue-induced relapse to cocaine seeking, with a reduction of cocaine-induced reinstatement of cocaine seeking in conditioned place preference (CPP) paradigm, and an increase in cue-induced reinstatement of cocaine SA. We also observed a reduction of motivation for cocaine SA after miR-1 overexpression in D2-SPNs of the DS. Altogether our data unveil a complex cell-type- and region-specific regulatory role for miR-1 in different relapse behaviors, and the importance of cell-specific investigations.

\section{MATERIALS AND METHODS}

More details on the materials and methods used are given in Supplementary Methods. Statistical details are given in Supplementary Materials.

\section{Animals and drug treatments}

All animal treatments and procedures were conducted in accordance with local and European directives for the care and use of laboratory animals
(86/609/EEC) and approved by the institutional French Animal Care Committee (agreement $\mathrm{N}^{\circ} 2010 / 63$ ) and by the Spanish local ethical committee (Comitè Ėtic d'Experimentació Animal-Parc de Recerca Biomèdica de Barcelona, CEEA-PRBB).

\section{Viral vectors}

For the overexpression of miR-1 in D1-SPNs or D2-SPNs of the striatum, we used a combination of AAVs (AAV9-PPTA-Cre or AAV9-PPE-Cre, respectively; titers: $1 \times 10^{12}$ in combination with AAV9-miR-1 flox or AAV9-miR-Scrlox titers: $1 \times 10^{12}$ genomic copies $/ \mathrm{mL}$ ). AAV-injected mice were used for experiments after at least three weeks for the full expression of viralmediated miRNA expression.

\section{Stereotaxic injections}

Mice were anesthetized using ketamine and xylazine (5:1 in amount; 0.1 $\mathrm{mL} / 10 \mathrm{~g}$ ), placed in a stereotaxic frame (David Kopf, Tujunga, CA), and $1 \mu \mathrm{l}$ in the NAc or $2 \mu \mathrm{l}$ in the DS was injected at a constant rate of $0.20 \mu \mathrm{l} / \mathrm{min}$ by using a microinfusion pump (Harvard Apparatus, Holliston, MA). We used the following coordinates to perform bilateral injections according to the mouse brain atlas of Paxinos and Franklin: NAc coordinates: AP + 1.4 $\mathrm{mm} ; \mathrm{ML} \pm 0.7 \mathrm{~mm} ; \mathrm{DV}-4.4 \mathrm{~mm}$;

DS coordinates: AP $+0.98 \mathrm{~mm} ; \mathrm{ML} \pm 1.75 \mathrm{~mm} ; \mathrm{DV}-3.5 \mathrm{~mm}$.

\section{Quantitative PCR analysis (qPCR) of miRNA and mRNA levels} Punches of NAC and DS were performed from frozen tissues and total RNA was isolated using miRNeasy MiniKit (Qiagen) according to the manufacturer's instructions. For mRNA levels analysis, total RNA (100 ng) isolated from each brain sample was reverse-transcribed with oligodT primers using RevertAid First Strand cDNA Synthesis Kit (ThermoFisher). For miRNA levels analysis, total RNA (100 ng) was reverse-transcribed using the same kit with a combination of specific RT-primers for each miRNA of interest ( 0.5 pmol of each RT-primer), as previously described [35], allowing high specificity, sensitivity and homogeneity. GPCR was performed with a LightCycler 480 device (Roche) using LightCycler SYBR Green I Master Mix (Roche) and specific couples of primers; samples were run in triplicates. The primers sequences for miRNAs and mRNAs are presented in Supplementary Fig. 1a, b, respectively.

\section{Luciferase assay to assess the interaction between miR-1 and the $3^{\prime}$ UTR of Bdnf, FosB and Npas4 in HEK cells}

The pmirGLO-3'UTR_Bdnf, pmirGLO-3'UTR_Fos $B$ and pmirGLO-3'UTR_Npas 4 plasmids were purchased from Creative Biogene and the mimick-miR$1 a-3 p$ and mimick-miR-negative control from Qiagen (miScript miRNA Mimics). The protocol used is described in https://doi.org/10.21769/ BioProtoc.420. The mean ratio of luminescence from the experimental reporter (firefly) to luminescence from the control reporter (Renilla) was calculated for each triplicate and normalized to the ratio of control wells (miRNA negative control which does not target the $3^{\prime} \mathrm{UTR}$ of mRNA of interest).

\section{Cocaine-induced behavioral responses}

The locomotor activity and its sensitization were evaluated using a circular corridor (actimeter) [36]. The cocaine-induced conditioned place preference (CPP), its extinction and reinstatement were evaluated in a plexiglas Y-shaped apparatus (Immetronic) with one arm blocked, located in a soundproof testing room with low luminosity using an unbiased procedure (see supplementary methods for more details). Two of the three chambers were used for the conditioning and distinguished by different floor textures and wall patterns. The device was connected to an electronic interface for data collection. Entries and time spent in each chamber were measured, as well as the locomotor activity of the mice during the experiments.

The operant self-administration of cocaine experiments were conducted in mouse operant chambers (Model ENV307A-CT; Med Associates Inc., Georgia, VT, USA) as previously described [37]. Nose pokes were the operant action that led to delivery of a cocaine infusion.

\section{Immunocytochemical studies}

The procedures for Cre-recombinase (anti-Cre-recombinase antibody; 1:500, mouse, MAB3120, Merck Millipore) is detailed in supplementary methods. 


\section{Statistical analysis}

All statistical analyses were carried out using GraphPad Prism and Statview softwares. For all experiments, ANOVAs were performed followed, when appropriate, by post-hoc test Bonferroni for multiple comparisons, except when data did not pass the normality test and/or when the number of individuals was too low. In those cases, non-parametric tests, such as Mann-Whitney (for two groups) or Kruskall-Wallis followed by post-hoc Dunn's test (for more than two groups) were used. The null hypothesis was rejected at $p<0.05$. All the statistical results for principal figures are reported in

\section{RESULTS}

Ten day cocaine exposure differentially regulates a subset of plasticity-related miRNAs in the NAC and DS

Several miRNAs have been shown to respond to 1-week cocaine exposure in a broad miRNA sequencing study [31]. Among those, we selected a subset of 14 miRNAs (miR-1, $-16,-29 b,-31,-32,-124$, $-125 a,-128 b,-132,-181 a,-212,-221,-223$ and Let7) based on their association either with cocaine addiction [25] or with other related brain disorders [24]. We measured the expression levels of these 14 miRNAs in the NAc and DS by RT-qPCR, after a one-week repeated treatment with cocaine mimicking a behavioral sensitization procedure (Fig. 1a) known to induce modifications in miRNAs expression [31]. The sequences of all miRNA primers used are presented in Supplementary Figure 1a. Interestingly, the repeated exposure to cocaine did not significantly alter miRNA levels in the DS but induced an upregulation of 11 of these 14 miRNAs in the NAc (Fig. 1b, c, left panels).

The mRNA expression levels of the key players in miRNA processing, such as Drosha, Dicer, Tar RNA Binding Protein (TRBP) and Ago2, were not modulated by cocaine (Fig. 1b, c, right panels), indicating that the observed miRNA regulation did not result from alterations in the general miRNA processing machinery at the mRNA level.

In order to predict cocaine-related target genes of the selected miRNAs, we used a combination of databases, including miRBase, Miranda, TargetScan and Tarbase, crossed with literature data on cocaine addiction. We identified 9 potential interesting targets: Bdnf, Fosb, Npas4, Gria2, Grin2b, Gria3, Pi3k, Drd1 and Mef2c (Fig. 1d) and studied expression levels of these mRNAs in the DS and NAc after our protocol of sustained cocaine administration. Among these mRNAs, we only observed a significant increase in the expression levels of FosB, Npas4 and Pi3k mRNAs in the DS, but not in the NAc where an increase in Bdnf expression was found (Fig. 1e).

\section{Validation of FosB and Npas4 mRNAs as targets of miR-1}

In most cases, miRNAs interact with the $3^{\prime} U T R$ of target mRNAs to induce mRNA degradation or translational repression [38]. We hypothesized that the absence of detectable upregulation of Fos $B$ and Npas4 mRNAs by cocaine in the NAc might be due to cocaineinduced upregulation of miRNA(s) targeting these mRNAs in this region. Among the selected miRNAs, we focused on miR-1 because the "in silico" prediction indicated that it potentially targeted both fosB and npas4 mRNAs (Fig. 1d), which are key players in cocaineinduced long-term adaptations [39, 40]. We experimentally tested whether these potential targets were directly bound by miR-1 (Fig. 2) using a luciferase reporter assay with constructs containing either FosB, Npas4 mRNA 3'UTRs (Fig. 2a, left panel), or the Bdnf 3'UTR as a positive control [41]. We observed a significant decrease in luciferase activity in HEK cells expressing the pmiRGlo plasmid encoding the $3^{\prime}$ UTR of Bdnf, FosB or Npas4 in the presence of a mimick-miR-1 when compared to the negative miR-control (Fig. 2a, right panels). We thus validated in vitro that the $3^{\prime}$ UTR of Bdnf, FosB and Npas4 is directly targeted by miR-1.

We further aimed to assess whether miR-1 could repress Bdnf, Fosb and Npas4 mRNA levels in vivo. To this end, we used an AAV- mediated cell-type-specific strategy allowing to overexpress miR-1 in either D1R-SPNs or D2R-SPNs. We used a combination of two AAVs, with one expressing miR-1 in a Cre recombinase-dependent manner and the other one expressing Cre under a cell-typespecific promoter (PPE-Cre and PPTA-Cre, expressed in D1R-SPNs and D2R-SPNs respectively) as previously validated [32-34] (Fig. 2b, e, see also Supplementary Fig. 2a, b). As compared to the control group (injected with an AAV expressing scrambled RNA, Scr) we found a marked increase in miR-1 levels after overexpression of miR-1 in D1R- or D2R-SPNs in either the DS (Fig. 2c, f) or the NAc (Fig. 2d, g), with a concomitant decrease in the expression of Fosb and Npas4 mRNAs, which was significant in several cases (Fig. $2 \mathrm{c}-\mathrm{g}$ ). We thus confirmed the ability of miR-1 to repress Fosb and Npas 4 mRNAs expression in vivo. Consistent with the preferential expression of Bdnf mRNA in axons from afferent excitatory cortical neurons [42], and their low levels in SPNs we failed to detect a significant effect of miR-1 overexpression on $B d n f$ mRNA levels in any conditions. miR-1 overexpression did not impact on the expression levels of mRNAs involved in miRNA processing, nor levels of miR-206 a miRNA from the same family than miR-1 (Supplementary Fig. 3a, b).

\section{Effects of miR-1 overexpression in D1- and D2R-SPNs of the} NAC and DS on cocaine-induced locomotor sensitization Having established the inhibitory role of miR-1 on Fosb and Npas4 mRNA expression levels, we investigated the potential role of miR1 overexpression on behavioral adaptations to cocaine. We specifically overexpressed miR-1 in D1- or D2-SPNs in regions where it is induced by cocaine (NAC) or not (DS). We first studied the consequences of this overexpression on cocaine-induced locomotor sensitization (15 mg/kg) (Supplementary Fig. 4a-e). The overexpression of miR-1 in either D1-SPNs or in D2-SPNs of the NAc or DS did not modify cocaine-induced locomotor activity or its sensitization (Supplementary Fig. 4b-e), indicating that miR-1 and its targets are not critical for the sensitizing effects of cocaine.

\section{Cell-type- and region-specific effects of miR-1 in cocaine- induced conditioned place preference}

We then measured the effects of cell-type-specific overexpression of miR-1 on the rewarding properties of cocaine using the cocaine-induced conditioned place preference (CPP) paradigm, which can be used as a proxy for the rewarding properties of cocaine. Overexpression of miR-1 in D1-SPNs of the DS did not alter cocaine-induced CPP (Fig. 3a, left panel). We then extinguished the CPP by freely exposing the mice to cocainepaired and unpaired environments after saline injection and observed that miR-1 overexpression in D1-SPNs of the DS did not modify CPP extinction (Fig. 3a, middle panel). In contrast, the reinstatement of cocaine CPP induced by an acute injection of cocaine after the extinction period $(15 \mathrm{mg} / \mathrm{kg})$ was prevented by miR-1 overexpression in DS D1-SPNs (Fig. 3a, right panel).

We measured the levels of miR-1 and its target genes in the DS of these mice $1 \mathrm{~h}$ after the start of the reinstatement test. As expected we found, high levels of miR-1 in both saline and cocaine miR-1injected groups, while miR-1 levels were not altered in control groups (Fig. 3b, left panel). miR-1 overexpression in D1-SPNs blunted Fosb and Npas4 mRNA upregulation observed in the control scramble group after cocaine-induced reinstatement of CPP (Fig. 3b, right panel). miR-1 overexpression in D1-SPNs of the NAc did not alter the development of cocaine-induced CPP, nor its extinction and cocaineinduced reinstatement (Fig. 3c). As shown in Fig. 4a, b, the overexpression of miR-1 in D2-SPNs of the DS or NAc had no consequence on cocaine-induced CPP, extinction or cocaine-induced reinstatement. These results indicate that miR1-overexpression in DS D1-SPNs may specifically alter cocaine-induced CPP reinstatement, indicating a role of miR-1 targeting these genes in this behavior. 
a

Cocaine Cocaine Cocaine Cocaine Cocaine

$(20 \mathrm{mg} / \mathrm{kg}) \quad(20 \mathrm{mg} / \mathrm{kg})(20 \mathrm{mg} / \mathrm{kg})(20 \mathrm{mg} / \mathrm{kg}) \quad(20 \mathrm{mg} / \mathrm{kg})$

\begin{tabular}{|c|c|c|c|c|c|c|}
\hline $\begin{array}{l}\text { or } \\
\text { saline }\end{array}$ & $\begin{array}{l}\text { or } \\
\text { saline }\end{array}$ & $\begin{array}{l}\text { or } \\
\text { saline }\end{array}$ & $\begin{array}{l}\text { or } \\
\text { saline }\end{array}$ & $\begin{array}{l}\text { or } \\
\text { saline }\end{array}$ & $\begin{array}{l}\text { or } \\
\text { saline }\end{array}$ & $\begin{array}{c}\text { Brain } \\
\text { extraction }\end{array}$ \\
\hline & d2 & $d 3$ & d4 4 & d5 & d10 & $\stackrel{\mathrm{In}}{\longrightarrow}$ \\
\hline
\end{tabular}

b
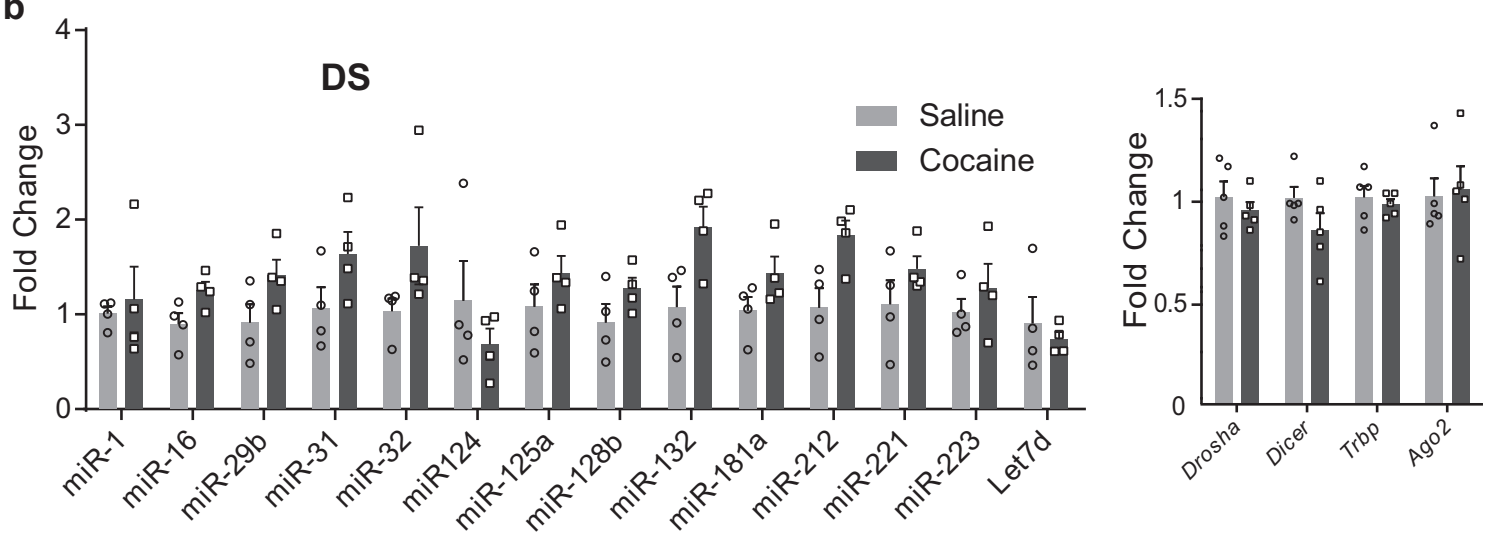

C
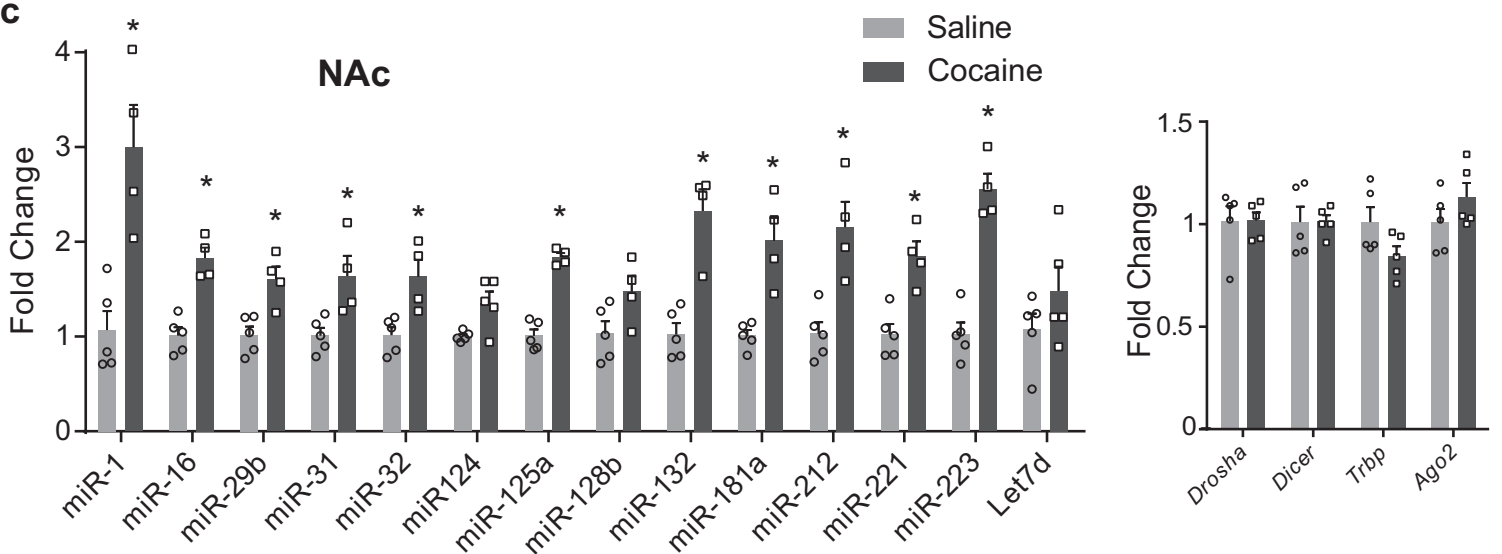

d

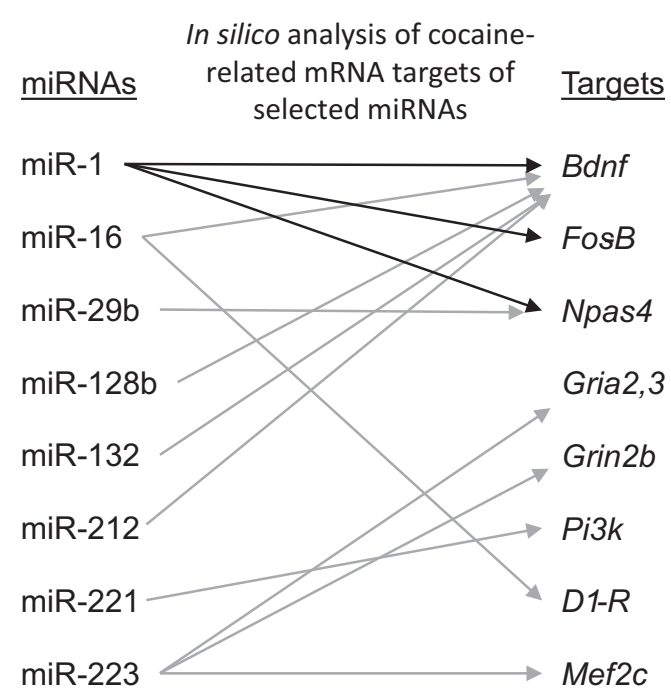

e DS

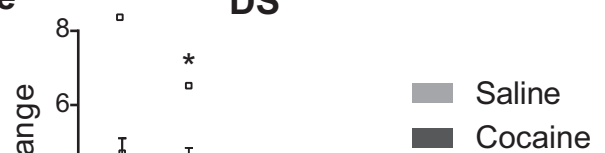

Fig. 1 A set of miRNAs is upregulated in the ventral (NAC), but not the dorsal (DS), striatum after sub-chronic treatment with cocaine. a Schematic representation of the timing of cocaine $(20 \mathrm{mg} / \mathrm{kg})$ or saline administrations and brain extraction. b, $\mathbf{c}$ Expression levels of miRNAs (left panels) and mRNAs involved in miRNA processing (right panels) were analyzed in the DS (b) and the NAc (c) one hour after the last injection of cocaine or saline on day 10. $\mathbf{d}$ In silico analysis of cocaine-related targets of miRNAs upregulated in the NAc, as indicated in (c). $\mathbf{e}$ Expression of predicted mRNA targets one hour after the last injection of cocaine or saline on day 10, in the DS (upper panel) or the NAC (lower panel). b, c, e Mean \pm SEM are represented. Mann-Whitney tests: ${ }^{*} p<0.05,{ }^{* *} p<0.01$ when comparing saline and cocaine groups. 
a

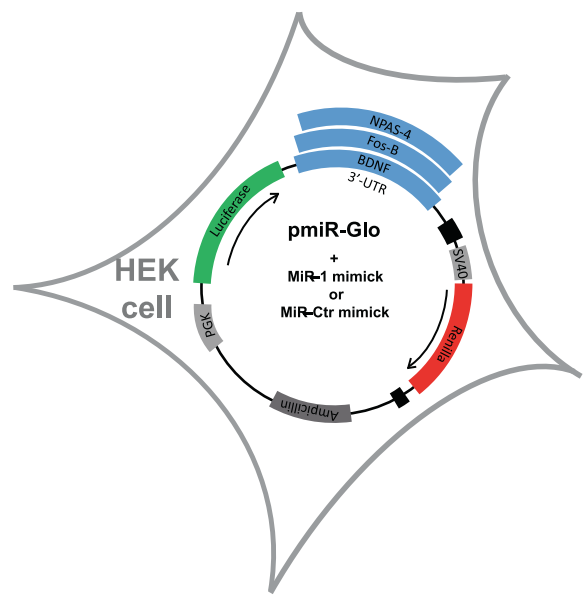

b

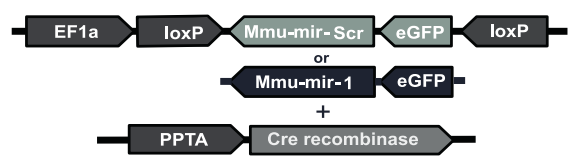

C

$$
\text { D1-SPN }
$$
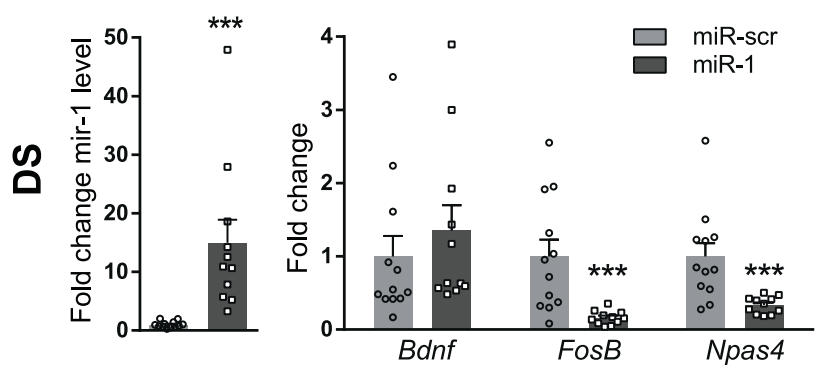

d

D1-SPN
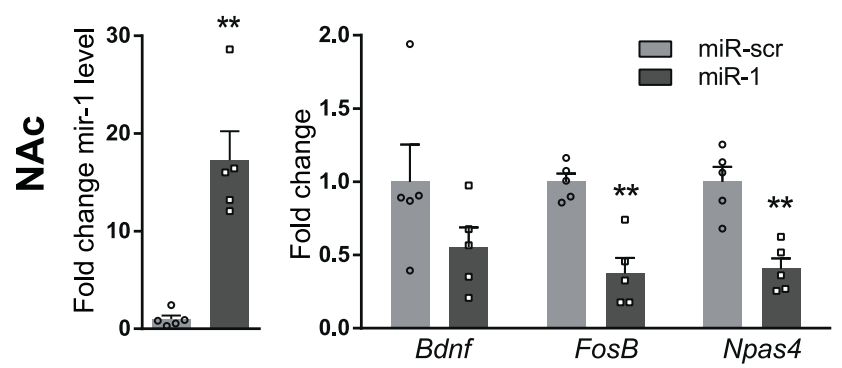

3'UTR sequence of miR-1 targets with complementarity with the seed sequence of miR-1

Bdnf $5^{\prime}$... UGGACAUAUCCAUGACCUGAAAGGAAACAGUCAUUUGCGCACAACUUUAAAAGUCUGCAUUACAUUCC

FosB $\quad 5^{\prime}$...CCCCGUGCUGCAUGgAaCAUUCCAUACCCUGUCCUGGGCCCUAGGUUCCAAACCUAAUCC... $3^{\prime}$

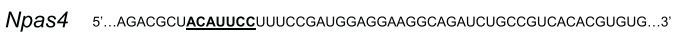

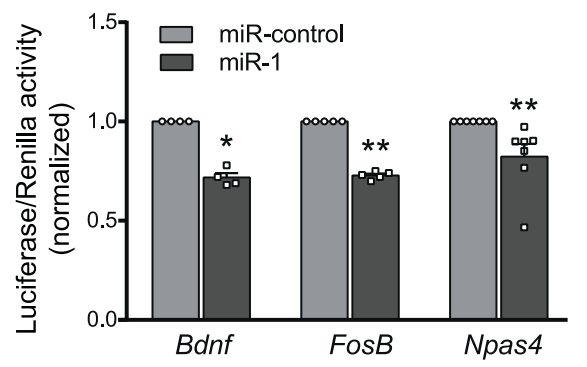

e

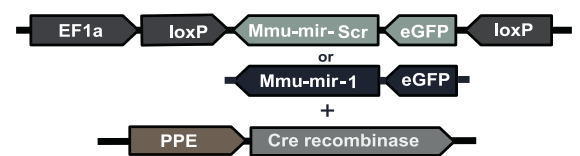

f

D2-SPN

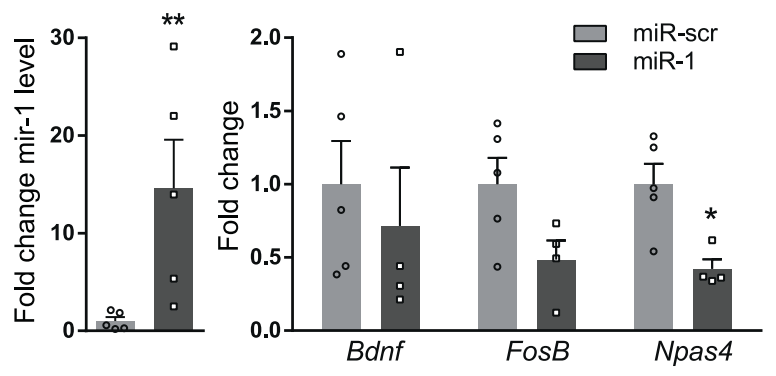

g

D2-SPN
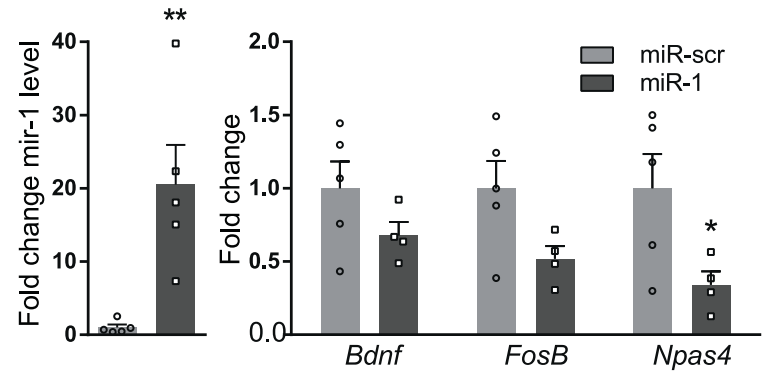

Fig. 2 Validation of miR-1 targets. a Left panel: schematic representation of the pmiR-Glo constructs used in HEK cells. Right Panel, up: $3^{\prime} U T R$ sequences of $b d n f$, fos $B$ and npas 4 mRNAs. Bold and underlined nucleotides represent complementarity with the seed sequence of miR-1; lower part: normalized Luciferase/Renilla activity of pmiR-Glo plasmid with bdnf, fos $B$ and npas $43^{\prime} U T R s$ mRNAs in the presence of miRNA mimics for miR-1 (black bars) or miR- control (gray bars). b-d overexpression of miR-1 in D1-SPN. $\mathbf{b}$ representation of the combination of AAVs to infect D1-SPNs. c, d normalized fold changes in expression of miR-1 (over miR-scr condition) (left panels) and bdnf, fos-B or $n p a s 4$ mRNA (right panels) after viral injection of miR-1 or miR-scr sequences in D1-SPNs of the DS (c) or the NAc (d) of mice. e-g overexpression of miR-1 in D2-SPNs. e representation of the combination of AAVs to infect D2-SPNs. $\mathbf{f}, \mathbf{g}$ normalized fold changes in expression of miR-1 (over miR-scr condition) (left panels) and bdnf, fos-B or npas4 mRNA (right panels) after viral injection of miR-1 or miR-scr sequences in D2-SPNs of the DS (f) or the NAc (g) of mice. $\mathbf{a}-\mathbf{g}$ Mean \pm SEM are represented. Mann-Whitney tests: ${ }^{*}: p<0.05 ;{ }^{* *}: p<0.01 ;{ }^{* *}: p<0.001$.

Cocaine self-administration, extinction and reinstatement after miR-1 overexpression in D1- or D2-SPNs of the DS of mice

We then investigated whether miR-1 overexpression in D1-SPNs of the DS altered cocaine SA. MiR-1 overexpression in DS D1-SPNs preserved the acquisition of $S A$, the motivation to self-administer cocaine assessed in a progressive ratio (PR) schedule of reinforcement (Fig. 5a, b), and the extinction of this behavior (Fig. 5c). By contrast, miR-1 overexpression in D1-SPNs of the DS induced a significant increased cue-induced reinstatement of cocaine seeking (Fig. 5 d). MiR-1 overexpression in D2-SPNs of the DS did not alter the acquisition of cocaine-SA (Fig. 5e). Interestingly, it reduced the breaking point for cocaine-SA under PR schedule of reinforcement (Fig. $5 f$, showing a reduced motivation 

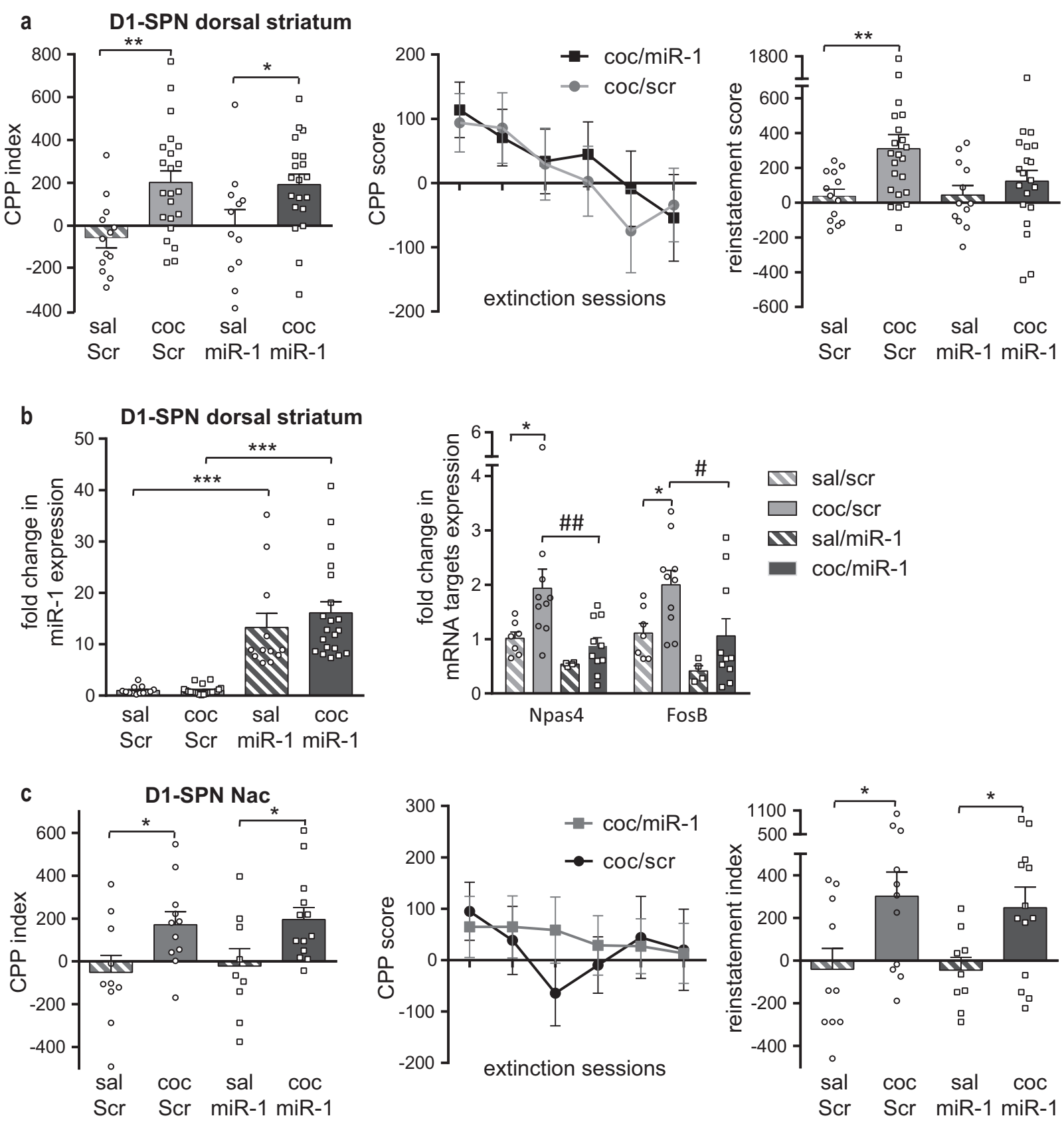

Fig. 3 Cocaine-induced conditioned place preference (CPP) and relapse in mice after miR-1 overexpression in D1-SPNs of the DS or NAc. a-b overexpression of miR-1 in D1-SPNs of the dorsal striatum. a Left panel: CPP after miR-1 overexpression in DS D1-SPNs. The CPP index is the difference of CPP score between the pretest and the test. The 2-way ANOVA indicated a significant effect of treatment, no effect of AAV and no interaction. Middle panel: extinction sessions for cocaine/miR-Scr and cocaine/miR-1 groups. The 2-way ANOVA indicated a significant effect of session but not of AAV and no interaction. Right panel: Cocaine-induced reinstatement of cocaine seeking after extinction in mice with miR-1 overexpression in D1-SPN of the dorsal striatum. The 2-way ANOVA indicated a significant effect of treatment, no effect of AAV and no interaction. Post-hoc tests: Bonferroni's multiple comparison tests: ${ }^{*} p<0.05 ;{ }^{* *} p<0.01$. b Left panel: expression of miR-1 after cocaineinduced reinstatement of cocaine seeking in mice with miR-1 or miR-Scr overexpression in D1-SPN of the DS. Right panel: normalized fold changes of expression levels of npas 4 and fos $B$ mRNA after cocaine-induced reinstatement of cocaine seeking in mice with miR-1 overexpression in D1SPN of the DS; The Kruskal-Wallis test on npas4 and fosB mRNAs expression levels indicated a significant group effect. The Post-hoc analysis (Dunn's multiple comparison test) indicated significant differences between the saline/miR-Scr and the cocaine/miR-Scr groups for both npas4 and fosB mRNAs: ${ }^{*} \mathrm{p}<0.05$ and between the cocaine/miR-Scr and the cocaine/miR-1 groups for both npas4 and fos $B$ mRNAs: ${ }^{\#} p<0.05 ;{ }^{\# \#} p<0.01$. c overexpression of miR-1 in D1-SPNs of the NAc. Left panel: CPP after miR-1 overexpression in D1-SPN of the NAc of mice. The CPP index is the difference of CPP score between the pretest and the test. Middle panel: extinction sessions for cocaine/miR-Scr and cocaine/miR-1 groups. Right panel: Cocaine-induced reinstatement of cocaine seeking after extinction in mice with miR-1 overexpression in D1-SPN of the NAc. Bonferroni's multiple comparison tests: ${ }^{*} p<0.05$. a-c Mean and SEM are represented. 


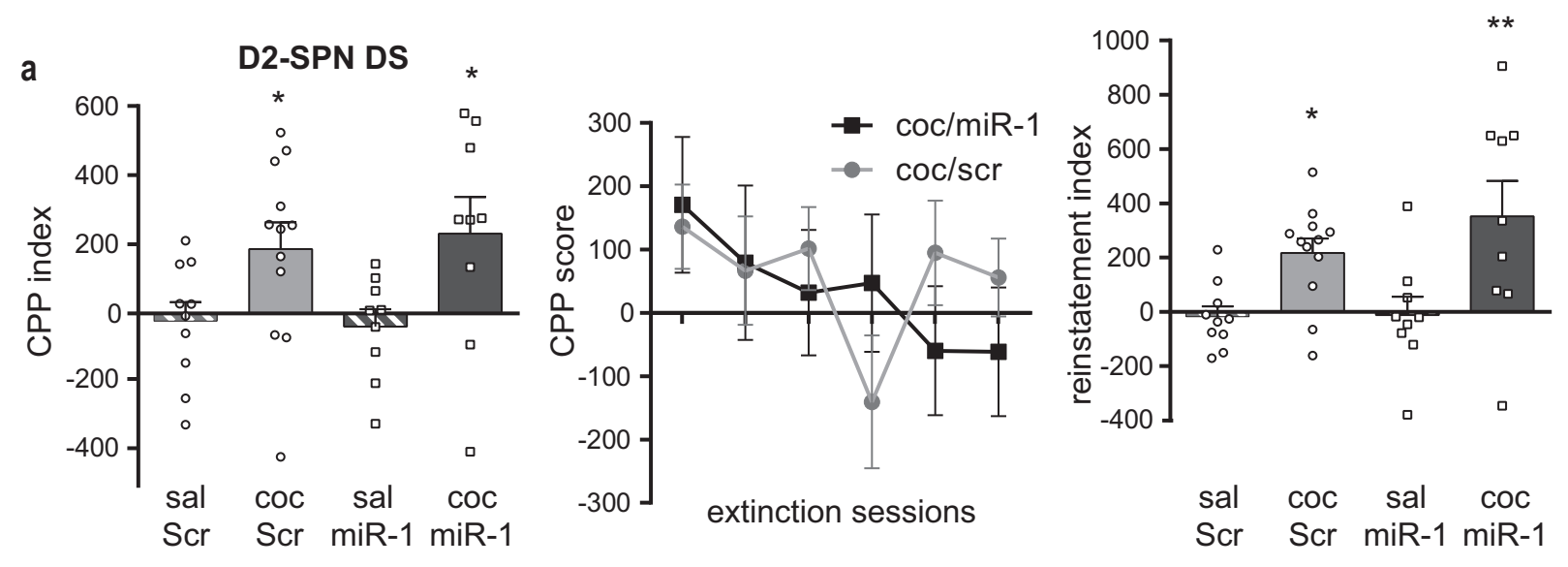

b
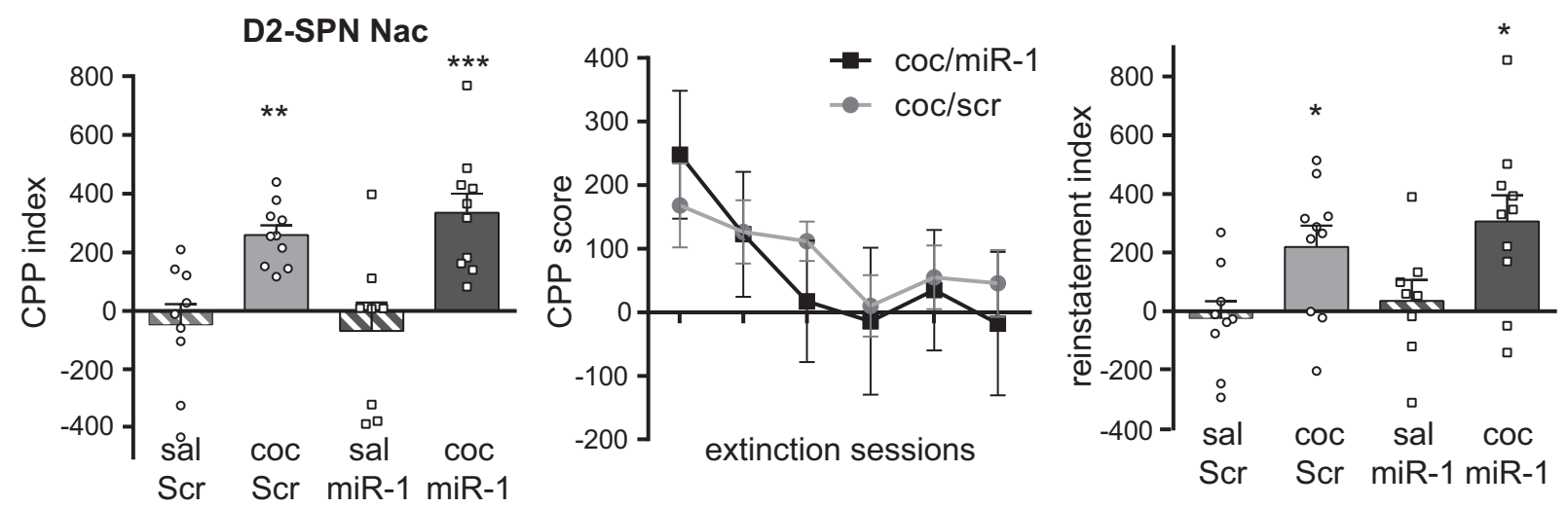

Fig. 4 Cocaine-induced conditioned place preference and relapse after miR-1 overexpression in D2-SPN of the dorsal striatum or NAc of mice. a miR-1 overexpression in D2-SPN of the dorsal striatum (DS) of mice. Left panel: CPP. The 2-way ANOVA performed on the CPP index indicated a significant effect of treatment but not of AAV and no interaction. Middle panel: extinction sessions for coc/ Scr and coc/miR-1 groups. The 2way ANOVA indicated a significant effect of session but not of AAV and no interaction. Right panel: Cocaine-induced reinstatement of cocaine seeking after extinction. The two-way ANOVA performed on the reinstatement index (difference of CPP score between the extinction and the reinstatement test) indicated a significant effect of treatment but not of AAV and no interaction. $\mathbf{b}$ miR-1 overexpression in D2-SPN of the NAc of mice. Left panel: CPP. The two-way ANOVA indicated a significant effect of treatment but not of AAV and no interaction. Middle panel: extinction sessions for $\mathrm{coc} / \mathrm{Scr}$ and $\mathrm{coc} / \mathrm{miR}-1$ groups. The 2-way ANOVA indicated a significant effect of session but not of AAV and no interaction. Right panel: Cocaine-induced reinstatement of cocaine seeking after extinction. The two-way ANOVA indicated a significant effect of treatment but not of AAV and no interaction. $\mathbf{a}, \mathbf{b}$ Mean \pm SEM are represented. Post-hoc Bonferroni's multiple comparison tests ${ }^{*} p<0.05 ;{ }^{* *} p<0.01 ;{ }^{* * *} p<0.001$.

to self-administer cocaine-SA upon miR-1 overexpression in D2SPN of the DS. In contrast to what we observed in D1-SPNs, miR-1 overexpression in D2-SPNs had no effect on SA extinction (Fig. $5 \mathrm{~g}$ ) or cue-induced reinstatement of cocaine seeking (Fig. $5 \mathrm{~h}$ ). Altogether these results establish a cell-type-specific function of miR- 1 and its target genes in the DS in controlling distinct components of cocaine-adaptative behaviors.

\section{DISCUSSION}

Our data show that miR-1 is upregulated in the NAc, but not the DS, by a 10-day regimen of cocaine and that at least three mRNAs encoding proteins associated with cocaine-induced neuronal plasticity, FOSB, NPAS4 and BDNF are targeted by miR-1. We also demonstrate that overexpression of miR-1 in D1-SPNs of the DS decreases cocaine-induced reinstatement of cocaine seeking in a CPP paradigm, but increases cue-induced reinstatement of cocaine seeking in a SA protocol. In addition, overexpression of miR-1 in D2-SPNs of the DS reduces the breaking point for cocaine-SA under a progressive ratio schedule of reinforcement. These results unveil the modulatory capacity of miR-1, and suggest that its target genes in DS neurons are involved in mediating specific aspects of cocaine-induced behavior.

Multiple miRNAs were reported to be modulated by cocaine [26]. In a miRNA profiling study, a panel of miRNAs was either upor downregulated by prolonged cocaine exposure [43]. Induction of miR-132 and miR-212 occurred in the DS after extended access to cocaine self-administration, and overexpression of miR-212 reduced compulsive cocaine intake in rats through CREB, MeCP2 and BDNF signaling $[44,45]$. In silico genome-wide sequencing identified miR-495 among miRNAs whose targets are enriched in an addiction-related gene (ARG) database. Lentiviral-mediated overexpression of miR-495 in the NAc suppressed the motivation to self-administer and seek cocaine [46].

Deficiency of Ago2 in D2-SPNs greatly influenced a specific group of miRNAs, and reduced approximately by half the expression of miR1 [27], suggesting that miR-1 is expressed in both types of SPNs in this structure. Similarly to our study, Hollander et al. (2010) showed that overexpression of miR-1 in the DS, failed to alter cocaine intake, but cell-type-specificity and reinstatement of drug seeking were not investigated [44]. Herein, we provide evidence that miR-1 targets the mRNA encoding the transcription factor FosB, the spliced version of 


\section{D1-SPNs}
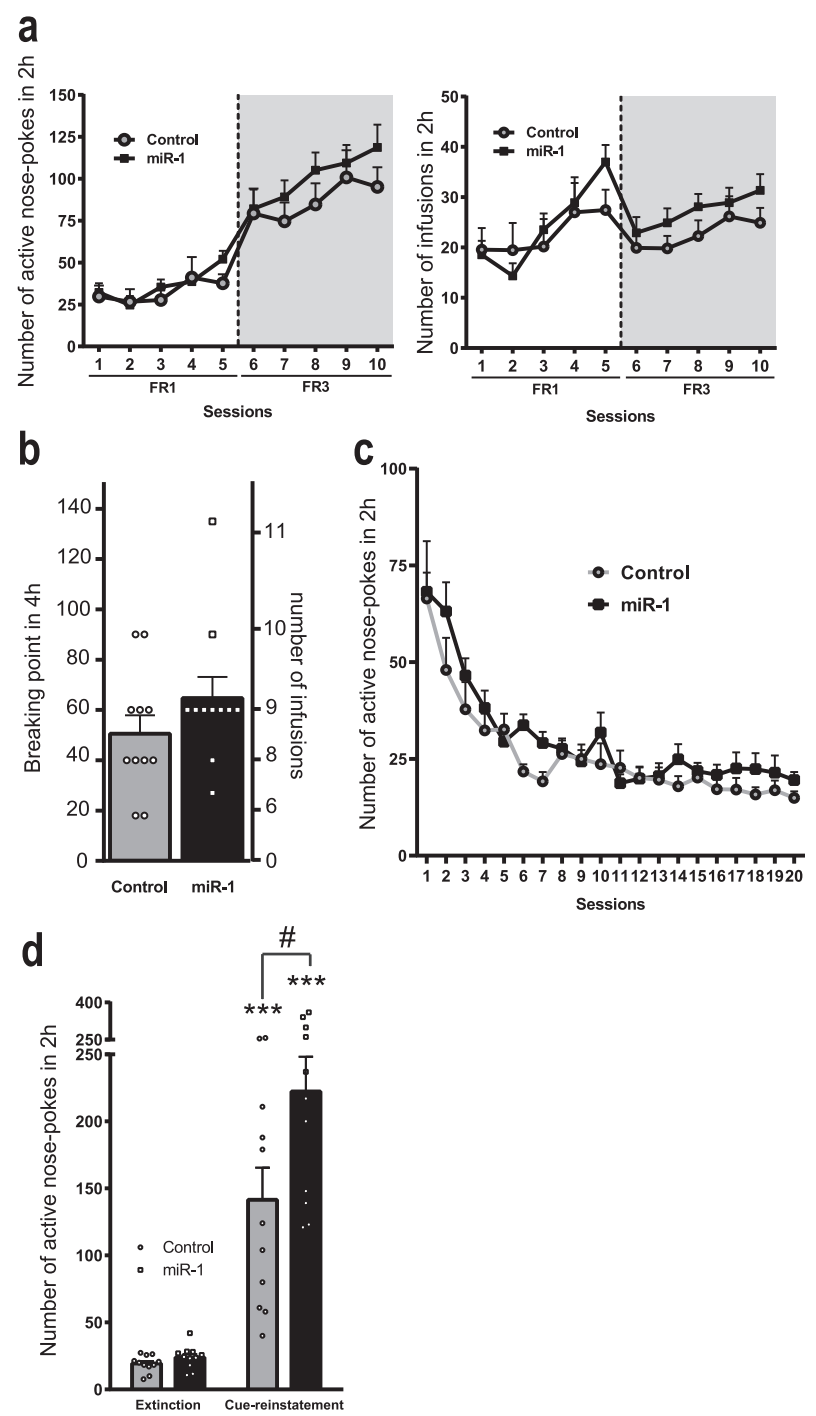

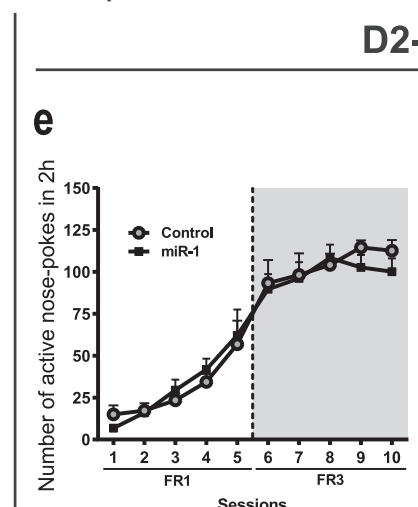

D2-SPNs

f
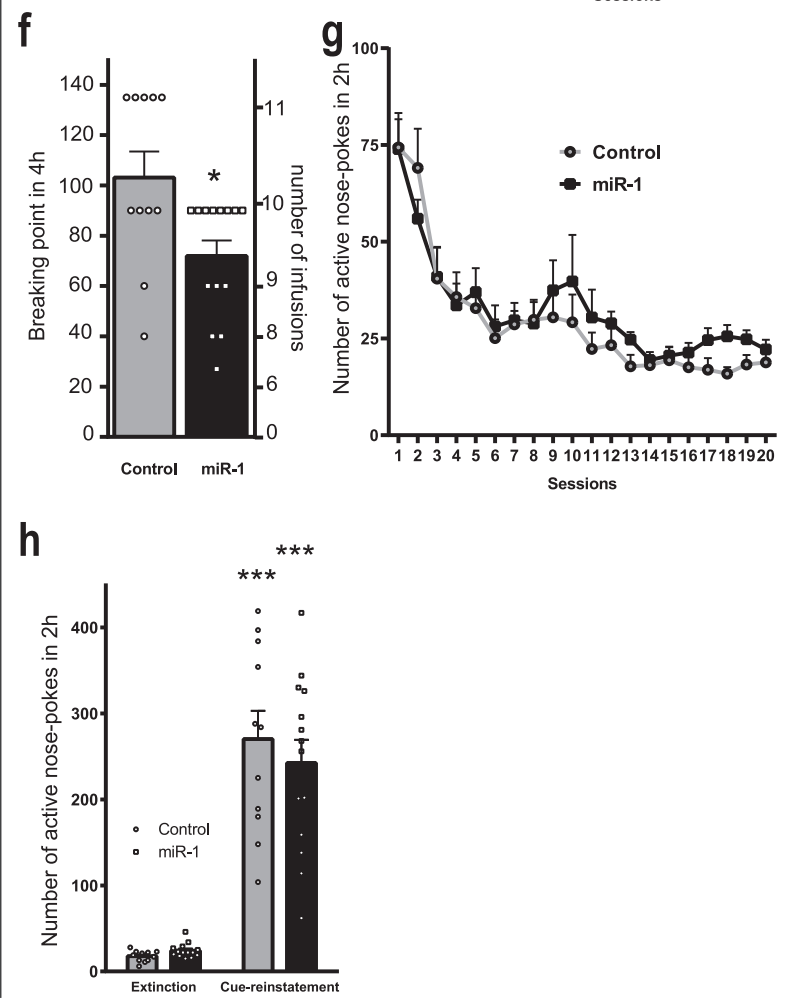

Fig. 5 Cocaine Self-Administration and relapse after extinction in mice with miR-1 overexpression in D1- or D2-SPNs of the dorsal striatum. a-e miR-1 overexpression in D1- SPNs of the dorsal striatum. a Cocaine Self-Administration. Left panel: active nose pokes during the acquisition of cocaine $(0.5 \mathrm{mg} / \mathrm{kg} /$ infusion)-induced self-administration in mice with $(n=11)$ or without $(n=11$, scr) miR-1 overexpression in the D1-SPNs of the DS. The 2-way ANOVA indicated no effect of miR-1 overexpression, a significant effect of session, and no interaction. Right panel: number of cocaine infusions received during the acquisition of cocaine-induced self-administration. The 2-way ANOVA indicated no effect of miR-1 overexpression), a significant effect of session and no interaction. $\mathbf{b}$ Breaking point for cocaine (0.5 mg/kg/infusion)-induced self-administration under a progressive ratio. The Mann-Whitney test indicated no AAV effect. c Active nose-pokes during the extinction sessions. The 2-way ANOVA indicated no effect of miR-1 overexpression, a significant effect of session and no interaction. $\mathbf{d}$ Cue-induced reinstatement of cocaine seeking after extinction (miR-1 overexpression in the D1-SPNs of the DS). The 2-way ANOVA indicated a significant effect of miR-1 overexpression, a significant effect of cue-reinstatement and a significant interaction. Post-hoc Bonferroni's multiple comparison test ${ }^{* *}: p<0.01$ (extinction vs cue-reinstatement); ${ }^{*} p<0.05$ (scr vs miR-1). e-h miR-1 overexpression in D2- SPNs of the dorsal striatum. e Cocaine Self-Administration. Left panel: active nose-pokes during the acquisition of cocaine (0.5 mg/kg/infusion)-induced selfadministration in mice with $(n=14)$ or without $(n=11, \mathrm{scr})$ miR-1 overexpression in the D2-SPNs of the DS. The 2-way ANOVA indicated no effect of miR-1 overexpression, a significant effect of session, and no interaction). Right panel: number of cocaine infusions received during the acquisition of cocaine-induced self-administration. The 2-way ANOVA indicated no effect of miR-1 overexpression, a significant effect of session and no interaction. f Breaking point for cocaine $(0.5 \mathrm{mg} / \mathrm{kg} / \mathrm{infusion})$-induced self-administration under a progressive ratio (miR-1 overexpression in the D2-SPNs of the DS). The Mann-Whitney test indicated a significant effect of miR-1 overexpression ( $p=0.018)$. $g$ Active nose-pokes during the extinction sessions after miR-1 overexpression in the D2-SPNs of the DS. The 2-way ANOVA indicated no effect of miR-1 overexpression, a significant effect of session and no interaction. h Cue-induced reinstatement of cocaine seeking after extinction. The 2-way ANOVA indicated no effect of miR-1 overexpression, a significant effect of cue-reinstatement and no interaction. Post-hoc Bonferroni's multiple comparison test ${ }^{* *}: p<0.01$ (extinction vs cue-reinstatement). a-h Mean \pm SEM are represented. 
which, $\triangle$ FosB, persistently accumulates in D1-SPN of the NAc after chronic psychostimulant exposure, and plays a key role in cocaine addiction [47]. This D1-SPN cell-type-specific $\Delta$ FosB expression induced by psychostimulant was further confirmed in reporter lines $[48,49]$ or using ribosomal tagging approaches [50]. Furthermore, $\triangle$ FosB overexpression in D1-SPN increases locomotor activity and rewarding effects of low doses of cocaine [51], as well as cocaine selfadministration [52]. Since miR-1 reduces the expression fosb mRNAs, which encodes both FosB and $\triangle F o s B$, it was surprising to observe that miR-1 overexpression in D1-SPNs of the NAc failed to alter cocaineinduced locomotor sensitization and CPP. However, the involvement of $\triangle \mathrm{FosB}$ in cocaine's effect seems highly dependent on the environment. For example, chronic cocaine treatment elevates $\Delta$ FosB protein levels in the NAc of isolated rats, but not in enriched conditions due to an already elevated basal accumulation of $\Delta \mathrm{FosB}$ [53]. Furthermore, the facilitating effects of $\Delta$ FosB overexpression in D1-SPN on cocaine-induced behaviors were seen in individually housed animals [52], In addition, overexpression of $\triangle F$ FosB in the NAc shell of pair-housed rats increases operant responding for sucrose when motivated by hunger, but decreases responding in satiated animals, in cocaine self-administration and cocaine-induced relapse. In our study, the mice were housed five per cage, and we did not observe a significant increase in fos $B$ mRNAs in the NAc upon sustained cocaine administration, similarly to previous studies in rats [53]. The absence of the effect of miR-1 overexpression in D1-SPNs of the NAC on cocaine-induced locomotor sensitization and CPP might thus be due to our environmental conditions. Alternatively, we cannot exclude that $\triangle$ FosB overexpression previously observed in D1-SPNs of the NAc [47-49] results from an accumulation of the stable protein rather than from de novo gene expression, or that a partial decrease induced by miR-1 overexpression may not be sufficient to prevent the behavior.

Another validated target of miR-1 was Bdnf mRNA encoding brain-derived neurotrophic factor (BDNF), which also plays a key role in cocaine-induced behaviors [54]. In particular, data from several labs suggest a facilitating effect of BDNF in the NAc on cocaine-induced CPP and cocaine-primed reinstatement $[55,56]$. However, the main source of BDNF within the striatum, including the $\mathrm{NAC}$, arises from prefrontal cortical neurons release [57], which mediates the majority of BDNF effects on cocaine-related behaviors [58]. By contrast, Bdnf mRNA levels are very low in the striatum under basal conditions, as observed in our RT-qPCR data. Altogether, these observations can explain the lack of effect of miR-1 overexpression on Bdnf mRNA levels in vivo, despite a clear demonstration that miR-1 targets its 3'UTR region in vitro. Further experiments, which are out of the scope of our study, could include overexpression of miR-1 in prefrontal cortical neurons.

Finally, we demonstrate that Npas4 is a target of miR-1 both in vitro and in vivo. Npas4 encodes NPAS4, an activity-dependent transcription factor that plays a key role in neuronal plasticity and is induced in the NAc by cocaine [40]. NPAS4 expression is higher in D1- than in D2-SPN in the NAc after cocaine-induced CPP [59] and NPAS4 positive cells co-express cFos [40], another activity-related immediate early gene, which is selectively induced by cocaine in D1-SPN [60]. Conditional deletion of Npas4 in the NAC significantly reduced cocaine-induced CPP and delayed the acquisition of cocaine-SA, without affecting cue-induced reinstatement of cocaine seeking [40]. In our study, miR-1 overexpression reduced but did not abolish Npas4 mRNA, a result that could explain its lack of effect in D1-SPN of the NAC on cocaine-induced CPP.

From a behavioral point of view, we found effects of miR-1 overexpression in D1-SPN of the DS on cocaine-induced reinstatement of cocaine CPP and cue-induced reinstatement of cocaine seeking in a self-administration paradigm. Thus, while miR-1 overexpression in DS D1-SPN blunted cocaine-induced reinstatement of $C P P$, it potentiated cue-induced reinstatement of self-administration. These differential effects on cocaine-induced reinstatement of a cocaine-induced CPP and on cue-induced reinstatement of cocaine-induced SA could be explained by differences in cocaine doses and routes of administration used in the two protocols, the time period of extinction and by the fact that the reinstatement of cocaine seeking is induced by a priming dose of cocaine for CPP and by a cue previously associated with cocaine (thus in cocaine-free state) in SA. This differential effect may be due to differences in neuronal circuits involved in each behavior (see [61-63] for reviews). It would have been interesting to evaluate the effect of miR-1 overexpression in D1-SPN on cocaine-induced reinstatement after SA and extinction, but cocaine priming does not induce reliable reinstatement of cocaine seeking in strain of mice (C57Bl6) [64] used in this study, contrasting with Swiss albino mice [65].

Finally, we found a decrease in breaking point for cocaine-SA under a PR schedule of reinforcement induced my miR-1 overexpression in D2-SPNs of the DS, suggesting a reduction in motivation for cocaine-SA. There are very few examples in the literature for specific reduction of motivation for cocaine-SA. D2SPNs of the DS are inhibitory neurons projecting to the external part of the globus pallidus (GPe), which contains inhibitory neurons projecting to the subthalamic nucleus (STN). The inhibition of D2-SPN activity thus results in an inhibition of STN activity. Of interest, either lesion or inhibition of STN neurons can lead to a reduction in the breaking point for cocaine-SA without altering SA under a fixed ratio schedule [66] much like what we observed in the present study.

In conclusion, our data show a specific and distinct role of miR-1 in cocaine- and cue-induced relapses of two different cocainedependent behaviors after an extinction period and on motivation for cocaine-SA. This contributes to the dissection of the mechanisms underlying addictive behaviors. Our results show the cell-type-specific and region-specific role of miR-1 and underline differences between cocaine- and cue-induced reinstatement in non-operant and operant paradigms. Although the expression of miR-1 is not induced in the DS after cocaine administration, our data provide valuable information about its role and the involvement of its targets FOSB and NPAS4 in specific neurons of the striatum in behaviors related to cocaine addiction and offers interesting therapeutic perspectives. Further studies investigating the effect of miR-1 knock-down in the VS will be interesting to test the intrinsic function of miR-1 in this structure. Altogether our results highlight the complexity of the control of addictive behaviors and emphasizes the importance of regional cell-type-specific investigations.

\section{REFERENCES}

1. Luscher C, Malenka RC. Drug-evoked synaptic plasticity in addiction: from molecular changes to circuit remodeling. Neuron. 2011;69:650-63.

2. Koob GF, Volkow ND. Neurocircuitry of addiction. Neuropsychopharmacology. 2010;35:217-38

3. Schultz W. Multiple reward signals in the brain. Nat Rev Neurosci. 2000;1:199-207.

4. Balleine BW, Delgado MR, Hikosaka O. The role of the dorsal striatum in reward and decision-making. J Neurosci. 2007;27:8161-5.

5. Kravitz AV, Kreitzer AC. Striatal mechanisms underlying movement, reinforcement, and punishment. Physiology. 2012;27:167-77.

6. Kravitz AV, Tye LD, Kreitzer AC. Distinct roles for direct and indirect pathway striatal neurons in reinforcement. Nat Neurosci. 2012;15:816-8.

7. Everitt BJ, Belin D, Economidou D, Pelloux Y, Dalley JW, Robbins TW. Review. Neural mechanisms underlying the vulnerability to develop compulsive drugseeking habits and addiction. Philos Trans $\mathrm{R}$ Soc Lond Ser B: Biol Sci. 2008;363:3125-35.

8. Everitt BJ, Robbins TW. From the ventral to the dorsal striatum: devolving views of their roles in drug addiction. Neurosci Biobehav Rev. 2013;37:194654.

9. Alexander GE, Crutcher MD. Functional architecture of basal ganglia circuits: neural substrates of parallel processing. Trends Neurosci. 1990;13:266-71.

10. Bateup HS, Santini E, Shen W, Birnbaum S, Valjent E, Surmeier DJ, et al. Distinct subclasses of medium spiny neurons differentially regulate striatal motor behaviors. Proc Natl Acad Sci USA. 2010;107:14845-50. 
11. Cui G, Jun SB, Jin X, Pham MD, Vogel SS, Lovinger DM, et al. Concurrent activation of striatal direct and indirect pathways during action initiation. Nature. 2013;494:238-42.

12. Bromberg-Martin ES, Matsumoto $M$, Hikosaka O. Dopamine in motivational control: rewarding, aversive, and alerting. Neuron. 2010;68:815-34.

13. Calabresi P, Picconi B, Tozzi A, Ghiglieri V, Di Filippo M. Direct and indirect pathways of basal ganglia: a critical reappraisal. Nat Neurosci. 2014;17:1022-30.

14. Soares-Cunha C, Coimbra B, Sousa N, Rodrigues AJ. Reappraising striatal D1- and D2neurons in reward and aversion. Neurosci Biobehav Rev. 2016;68:37086.

15. Vicente AM, Galvao-Ferreira P, Tecuapetla F, Costa RM. Direct and indirect dorsolateral striatum pathways reinforce different action strategies. Curr Biol. 2016;26:R267-9.

16. Salery $M$, Trifilieff $P$, Caboche J, Vanhoutte $P$. From signaling molecules to circuits and behaviors: cell-type-specific adaptations to psychostimulant exposure in the striatum. Biol Psychiatry. 2020;87:944-53.

17. Lobo MK, Covington HE 3rd, Chaudhury D, Friedman AK, Sun H, Damez-Werno D, et al. Cell type-specific loss of BDNF signaling mimics optogenetic control of cocaine reward. Science 2010;330:385-90.

18. Bock R, Shin JH, Kaplan AR, Dobi A, Markey E, Kramer PF, et al. Strengthening the accumbal indirect pathway promotes resilience to compulsive cocaine use. Nat Neurosci. 2013;16:632-8.

19. Calipari ES, Bagot RC, Purushothaman I, Davidson TJ, Yorgason JT, Pena CJ, et al. In vivo imaging identifies temporal signature of D1 and D2 medium spiny neurons in cocaine reward. Proc Natl Acad Sci USA. 2016;113:2726-31.

20. Yager LM, Garcia AF, Donckels EA, Ferguson SM. Chemogenetic inhibition of direct pathway striatal neurons normalizes pathological, cue-induced reinstatement of drugseeking in rats. Addiction Biol. 2019;24:251-64.

21. Nestler EJ. Epigenetic mechanisms of drug addiction. Neuropharmacology. 2014;76:259-68.

22. Bird A. Perceptions of epigenetics. Nature. 2007;447:396-8.

23. Bartel DP. MicroRNAs: target recognition and regulatory functions. Cell. 2009;136:215-33.

24. Im HI, Kenny PJ. MicroRNAs in neuronal function and dysfunction. Trends Neurosci. 2012;35:325-34.

25. Heyer MP, Kenny PJ. Corticostriatal microRNAs in addiction. Brain Res. 2015;1628:2-16.

26. Smith ACW, Kenny PJ. MicroRNAs regulate synaptic plasticity underlying drug addiction. Genes Brain Behav. 2018;17:e12424.

27. Schaefer A, Im HI, Veno MT, Fowler CD, Min A, Intrator A, et al. Argonaute 2 in dopamine 2 receptor-expressing neurons regulates cocaine addiction. J Exp Med. 2010;207:1843-51.

28. Hammond SM, Boettcher S, Caudy AA, Kobayashi R, Hannon GJ. Argonaute2, a link between genetic and biochemical analyses of RNAi. Science 2001;293:1146-50.

29. Diederichs $S$, Haber DA. Dual role for argonautes in microRNA processing and posttranscriptional regulation of microRNA expression. Cell 2007;131:1097-108.

30. O'Carroll D, Mecklenbrauker I, Das PP, Santana A, Koenig U, Enright AJ, et al. A Slicerindependent role for Argonaute 2 in hematopoiesis and the microRNA pathway. Genes Dev. 2007;21:1999-2004.

31. Eipper-Mains JE, Kiraly DD, Palakodeti D, Mains RE, Eipper BA, Graveley BR. microRNASeq reveals cocaine-regulated expression of striatal microRNAs. RNA. 2011;17:152943.

32. Yagishita S, Hayashi-Takagi A, Ellis-Davies GC, Urakubo H, Ishii S, Kasai H. A critical time window for dopamine actions on the structural plasticity of dendritic spines. Science. 2014;345:1616-20.

33. Dos Santos M, Salery M, Forget B, Garcia Perez MA, Betuing S, Boudier T, et al. Rapid synaptogenesis in the nucleus accumbens is induced by a single cocaine administration and stabilized by mitogen-activated protein kinase interacting kinase-1 activity. Biol Psychiatry. 2017;82:806-18.

34. Hikida T, Kimura K, Wada N, Funabiki K, Nakanishi S. Distinct roles of synaptic transmission in direct and indirect striatal pathways to reward and aversive behavior. Neuron. 2010;66:896-907.

35. Wang X. A PCR-based platform for microRNA expression profiling studies. RNA. 2009;15:716-23.

36. Lanteri C, Hernandez Vallejo SJ, Salomon L, Doucet EL, Godeheu G, Torrens Y, et al. Inhibition of monoamine oxidases desensitizes 5-HT1A autoreceptors and allows nicotine to induce a neurochemical and behavioral sensitization. J Neurosci. 2009;29:987-97.

37. Martin-Garcia E, Bourgoin L, Cathala A, Kasanetz F, Mondesir M, GutierrezRodriguez $A$, et al. Differential control of cocaine self-administration by GABAergic and glutamatergic CB1 cannabinoid receptors. Neuropsychopharmacology. 2016;41:2192205.

38. O'Brien J, Hayder $H$, Zayed $Y$, Peng C. Overview of MicroRNA biogenesis, mechanisms of actions, and circulation. Front Endocrinol. 2018;9:402.
39. Nestler EJ. Molecular neurobiology of addiction. Am J Addictions. 2001;10:201-17.

40. Taniguchi M, Carreira MB, Cooper YA, Bobadilla AC, Heinsbroek JA, Koike N, et al. HDAC5 and its target gene, Npas4, function in the nucleus accumbens to regulate cocaine-conditioned behaviors. Neuron 2017;96:130-44 e6.

41. Varendi K, Kumar A, Harma MA, Andressoo JO. miR-1, miR-10b, miR-155, and miR191 are novel regulators of BDNF. Cell Mol Life Sci. 2014;71:4443-56.

42. Hofer M, Pagliusi SR, Hohn A, Leibrock J, Barde YA. Regional distribution of brainderived neurotrophic factor mRNA in the adult mouse brain. EMBO J. 1990;9:245964.

43. Chandrasekar V, Dreyer JL. microRNAs miR-124, let-7d and miR-181a regulate cocaineinduced plasticity. Mol Cell Neurosci. 2009;42:350-62.

44. Hollander JA, Im HI, Amelio AL, Kocerha J, Bali P, Lu Q, et al. Striatal microRNA controls cocaine intake through CREB signalling. Nature. 2010;466:197-202.

45. Im HI, Hollander JA, Bali P, Kenny PJ. MeCP2 controls BDNF expression and cocaine intake through homeostatic interactions with microRNA-212. Nat Neurosci. 2010;13:1120-7.

46. Bastle RM, Oliver RJ, Gardiner AS, Pentkowski NS, Bolognani F, Allan AM, et al. In silico identification and in vivo validation of miR-495 as a novel regulator of motivation for cocaine that targets multiple addiction-related networks in the nucleus accumbens. Mol Psychiatry. 2018;23:434-43.

47. Nestler EJ, Barrot M, Self DW. DeltaFosB: a sustained molecular switch for addiction. Proc Natl Acad Sci USA. 2001;98:11042-6.

48. Lee KW, Kim Y, Kim AM, Helmin K, Nairn AC, Greengard P. Cocaine-induced dendritic spine formation in D1 and D2 dopamine receptor-containing medium spiny neurons in nucleus accumbens. Proc Natl Acad Sci USA. 2006;103:3399-404.

49. Lobo MK, Zaman S, Damez-Werno DM, Koo JW, Bagot RC, DiNieri JA, et al. DeltaFosB induction in striatal medium spiny neuron subtypes in response to chronic pharmacological, emotional, and optogenetic stimuli. J Neurosci. 2013:33:18381-95.

50. Heiman M, Schaefer A, Gong S, Peterson JD, Day M, Ramsey KE, et al. A translational profiling approach for the molecular characterization of CNS cell types. Cell. 2008;135:738-48.

51. Kelz MB, Chen J, Carlezon WA Jr, Whisler K, Gilden L, Beckmann AM, et al. Expression of the transcription factor deltaFosB in the brain controls sensitivity to cocaine. Nature. 1999:401:272-6.

52. Colby CR, Whisler K, Steffen C, Nestler EJ, Self DW. Striatal cell type-specific overexpression of DeltaFosB enhances incentive for cocaine. J Neurosci. 2003;23:2488-93.

53. Zhang Y, Crofton EJ, Li D, Lobo MK, Fan X, Nestler EJ, et al. Overexpression of DeltaFosB in nucleus accumbens mimics the protective addiction phenotype, but not the protective depression phenotype of environmental enrichment. Front Behav Neurosci. 2014;8:297.

54. Ghitza UE, Zhai H, Wu P, Airavaara M, Shaham Y, Lu L. Role of BDNF and GDNF in drug reward and relapse: a review. Neurosci Biobehav Rev. 2010;35:15771.

55. Graham DL, Krishnan V, Larson EB, Graham A, Edwards S, Bachtell RK, et al. Tropomyosin-related kinase $B$ in the mesolimbic dopamine system: regionspecific effects on cocaine reward. Biol Psychiatry. 2009;65:696-701.

56. Bahi A, Boyer F, Chandrasekar V, Dreyer JL. Role of accumbens BDNF and TrkB in cocaine-induced psychomotor sensitization, conditioned-place preference, and reinstatement in rats. Psychopharmacology. 2008;199:169-82.

57. Altar CA, Cai N, Bliven T, Juhasz M, Conner JM, Acheson AL, et al. Anterograde transport of brain-derived neurotrophic factor and its role in the brain. Nature. 1997;389:856-60.

58. McGinty JF, Whitfield TW Jr, Berglind WJ. Brain-derived neurotrophic factor and cocaine addiction. Brain Res. 2010;1314:183-93.

59. Funahashi Y, Ariza A, Emi R, Xu Y, Shan W, Suzuki K, et al. Phosphorylation of Npas4 by MAPK regulates reward-related gene expression and behaviors. Cell Rep. 2019;29:3235-52 e9.

60. Chandra R, Lobo MK. Beyond neuronal activity markers: select immediate early genes in striatal neuron subtypes functionally mediate psychostimulant addiction. Front Behav Neurosci. 2017;11:112.

61. Kalivas PW, McFarland K. Brain circuitry and the reinstatement of cocaine-seeking behavior. Psychopharmacology. 2003;168:44-56.

62. Farrell MR, Schoch $\mathrm{H}$, Mahler SV. Modeling cocaine relapse in rodents: Behavioral considerations and circuit mechanisms. Prog Neuro-Psychopharmacol Biol Psychiatry. 2018;87:33-47.

63. Sanchis-Segura C, Spanagel R. Behavioural assessment of drug reinforcement and addictive features in rodents: an overview. Addiction Biol. 2006;11:2-38.

64. Gutierrez-Cuesta J, Burokas A, Mancino S, Kummer S, Martin-Garcia E, Maldonado R. Effects of genetic deletion of endogenous opioid system components on the reinstatement of cocaine-seeking behavior in mice. Neuropsychopharmacology. 2014;39:297488. 
65. Soria G, Barbano MF, Maldonado R, Valverde O. A reliable method to study cue-, priming-, and stress-induced reinstatement of cocaine self-administration in mice. Psychopharmacology. 2008;199:593-603.

66. Rouaud T, Lardeux S, Panayotis N, Paleressompoulle D, Cador M, Baunez C. Reducing the desire for cocaine with subthalamic nucleus deep brain stimulation. Proc Natl Acad Sci USA. 2010;107:1196-2000.

\section{ACKNOWLEDGEMENTS}

The authors thank the participation of Guillaume Ubiema for some immunohistochemcal studies in vivo. We would particularly like to thank the whole team of Jocelyne Caboche for its encouraging support and help to the work.

\section{AUTHOR CONTRIBUTIONS}

B.F. and J.C. designed the study and wrote the manuscript. B.F. performed the vira injections, cocaine-induced locomotor sensitization and conditioned place preference experiments, RT-qPCR experiments and in vitro experiments. A.G. performed RT-qPCR experiments and participated in the writing of the manuscript. E.M.G E.S.M., and L.D.R. performed the cocaine-self-administration experiment. V.K. M.M., and M.C. A participated in the RT-qPCR and immunofluorescence experiments. P.P. performed most of the in vitro experiments and participated in the RT-qPCR experiments. A.A. performed viral infections and immunofluorescence experiments for tracing D1 and D2 striatal pathways. R.M. designed the cocaine self-administration experiments. P.V., J.A.G., and R.M. participated in experimental design and writing of the manuscript.

\section{FUNDING}

This work was supported by Fondation pour la Recherche Médicale (DEQ20150734352 to JC), Centre National pour la Recherche Scientifique (CNRS, B.F., A.G., V.K., P.P., P.V., J. C.), Institut National pour la Santé et la Recherche Médicale (INSERM; B.F., A.G., V.K., P. P., P.V., J.-A.G., J.C.), Sorbonne Université, Faculté des Sciences et Ingénierie (B.F., A.G., V. K., P.P., P.V., J.-A.G., J.C.) Labex Biopsy Investissements d'Avenir, ANR-11-IDEX-0004-02 (B.F., A.G., V.K., P.P., P.V., J.-A.G., J.C.), the Spanish Ministerio de Economía y Competitividad-MINECO (\#SAF2017-84060-R-AEI/FEDER-UE; E.M.-G., L.D.-R., R.M.), the Spanish Instituto de Salud Carlos III, RETICS-RTA (\#RD12/0028/0023; E.M.-G., L.D.-R., R. M.), the Generalitat de Catalunya, AGAUR (\#2017-SGR-669; E.M.-G., L.D.-R., R.M.), ICREA-Acadèmia (\#2015) and the Spanish Ministerio de Sanidad, Servicios Sociales e
Igualdad, Plan Nacional Sobre Drogas (\#PNSD-20171068) to R.M., Fundació La MaratóTV3 (\#2016/20-30) to E.M.-G. Fondation pour la Recherche Médicale (FRM\#DPA20140629798) and ANR (ANR-16-CE16-0018) to J.A.G.

\section{COMPETING INTERESTS}

The authors declare no competing interests.

\section{ADDITIONAL INFORMATION}

Supplementary information The online version contains supplementary material available at https://doi.org/10.1038/s41380-021-01328-2.

Correspondence and requests for materials should be addressed to Benoit Forget or Jocelyne Caboche.

Reprints and permission information is available at http://www.nature.com/ reprints

Publisher's note Springer Nature remains neutral with regard to jurisdictional claims in published maps and institutional affiliations.

Open Access This article is licensed under a Creative Commons Attribution 4.0 International License, which permits use, sharing, adaptation, distribution and reproduction in any medium or format, as long as you give appropriate credit to the original author(s) and the source, provide a link to the Creative Commons license, and indicate if changes were made. The images or other third party material in this article are included in the article's Creative Commons license, unless indicated otherwise in a credit line to the material. If material is not included in the article's Creative Commons license and your intended use is not permitted by statutory regulation or exceeds the permitted use, you will need to obtain permission directly from the copyright holder. To view a copy of this license, visit http://creativecommons. org/licenses/by/4.0/.

(C) The Author(s) 2021 